\title{
Explorando as TIC na formação inicial de professores de Educação Física: uma experiência com danças folclóricas.
}

\author{
Irlla Karla dos Santos Diniz ${ }^{1}$, Suraya Cristina Darido ${ }^{1}$ \\ ${ }^{1}$ Instituto de Biociências - Universidade Estadual Paulista (UNESP) \\ Av. 24A, 1515, 13506-900 - Rio Claro - SP- Brasil \\ irllakarla@yahoo.com.br, surayacderc.unesp.br
}

\begin{abstract}
Resumo. $O$ objetivo do presente estudo foi analisar algumas possibilidades didáticas com a utilização das TIC no ensino das danças folclóricas durante a formação inicial de professores de Educação Física. De modo específico, foi selecionado o xaxado uma vez que este conteúdo é proposto pelo Currículo de Educação Física vigente no Estado de São Paulo. Desenvolveu-se uma pesquisa qualitativa descritiva pontuando-se aspectos considerados relevantes. Os participantes do estudo avaliaram como importante explorar as TIC durante o processo formativo, visto que estas estratégias podem facilitar a transposição didática dos conhecimentos para a prática pedagógica, corroborando com novas formas de compreender os conteúdos da área.
\end{abstract}

\section{Exploring ICT in initial teacher of Physical Education: an experiment with folk dances.}

\begin{abstract}
The aim of this study was to analyze some possibilities with the didactic use of ICT in teaching folk dances during the initial training of physical education teachers. Specifically, we selected the xaxado since this content is proposed by the Physical Education Curriculum in force in the State of São Paulo. It was developed a descriptive qualitative research pointing relevant aspects. Study participants rated it as important to explore ICT during the training process, as these strategies may facilitate didactic transposition of knowledge for pedagogical practice, supporting new ways of understanding the contents of the area.
\end{abstract}

\section{Introdução}

A Educação Física (EF) é uma disciplina escolar que reúne um conjunto de práticas corporais que tratam o indivíduo em suas dimensões física, humana, psicológica, social, afetiva, cognitiva e política. Tais práticas fazem parte do acervo da cultural corporal, que foi construído e transformado ao longo do desenvolvimento da humanidade. As práticas que representam esta categoria são os jogos, o esporte, a dança, as lutas e a ginástica, elementos que na atualidade são consideradas os conteúdos da Educação Física escolar.

Darido e Souza Júnior (2007) corroboram com esta premissa ao afirmar que a Educação Física se constitui em uma disciplina curricular voltada a introduzir e integrar o aluno na esfera da cultura corporal, instrumentalizando-os para usufruir destes componentes. Gradativamente, esta disciplina também começa a se inserir em 
discussões envolvendo inovações pedagógicas e a utilização de tecnologias em espaços educacionais.

Atualmente, a sociedade está enfrentando um processo acelerado de transformação que tem provocado modificações significativas em suas formas de organização, atuação social, política e econômica, no lazer e no trabalho, além das esferas que envolvem comportamentos e valores. Este contexto está sendo delineado devido ao amplo desenvolvimento tecnológico que tem caracterizado a sociedade moderna nos últimos anos.

Os meios de comunicação e informação, em específico, passaram por uma revolução, o que permite observar mudanças radicais em diversos mecanismos telemáticos. Neste escopo, materializam-se as chamadas Tecnologias da Informação e Comunicação (TIC) que passaram a se inserir sistematicamente nos centros metropolitanos, disseminando-se gradativamente entre as diferentes classes sociais. Assim, inicia-se um processo com características e necessidades diferentes, incluindo discussões em meandros cada vez mais tecnológicos.

Para Sancho (2006) as TIC possuem um caráter transformador que atinge diretamente a forma como as pessoas pensam, lidam e agem com relação às diferentes situações do cotidiano, além de proporcionar novos locais para troca de informações, ou seja, o ciberespaço.

A aceitação das tecnologias como um elemento definidor desta realidade social, permite entender este estágio como aquele em que a humanidade mais desenvolveu suas potencialidades (Abranches, 2003). O mesmo autor destaca que a superação dos limites temporais por meio das redes telemáticas, o aumento da comunicação de modo instantâneo, e o desenvolvimento de outra forma de entendimento da vida, de modo cada vez mais virtual, são alguns dados significativos que caracterizam esta nova era da sociedade mundial (Abranches, 2003).

Assim, fica mais fácil identificar como todo este avanço tecnológico exerceu forte impacto sobre as diversas instituições sociais, bem como nas relações familiares, na cultura, na identidade e consequentemente na educação (Belloni, 2005). Bianchi e Hatje (2007) afirmam que esta evolução ao reconfigurar as formas de tempo e espaço tem provocado justamente estas rápidas transformações nas diferentes formas de representações sociais que precisam ser refletidas e analisadas com responsabilidade crítica.

No que tange o processo educacional, faz-se necessário ampliar os espaços de debate, visto que a inserção das tecnologias em ambientes educacionais parece não ter acompanhado o mesmo ritmo das demais instituições sociais, existindo a necessidade de entender como este processo tem ocorrido. Ademais, a possibilidade de pontuar algumas estratégias didático-pedagógicas que estes meios podem proporcionar durante a formação inicial de professores de Educação Física, é considerada relevante visto que pode aproximar os conteúdos curriculares de meandros tão significativos para a vida dos alunos.

Todavia, será que os futuros professores de Educação Física pensam em possibilidades didáticas para tratar as TIC em suas aulas? Existe espaço na formação inicial para debater e refletir sobre estas questões? 
Para tanto, o objetivo do presente estudo foi analisar algumas possibilidades didáticas com a utilização das TIC no ensino das danças folclóricas durante a formação inicial de professores de Educação Física.

\section{TIC na Educação Física}

A Educação Física enquanto um componente curricular obrigatório da Educação Básica, não pode ser excluída dos debates acerca da inserção das tecnologias no meio escolar. Nos Parâmetros Curriculares Nacionais do Ensino Médio (Brasil, 2000), esta disciplina foi inserida na área de Linguagens Códigos e suas Tecnologias (Grifo nosso), acentuando a necessidade da área também se debruçar sobre estas questões.

Apesar do documento não apresentar justificativas para esta classificação, esta disciplina é entendida como integrante das diversas formas de comunicação e precisa atender a esta demanda, na medida em que se propõem a debater e refletir sobre a cultura.

Darido e Rangel (2005, p. 34) entendem a Educação Física como uma prática pedagógica cuja função é "formar os cidadãos que irão usufruir, partilhar, produzir, reproduzir e transformar as manifestações que caracterizam essa área, tais como: o Jogo, o Esporte, a Dança, a Ginástica e a Luta". Ou seja, esta disciplina compreende um conjunto de práticas corporais constituintes da cultura, e assim, deve ser contextualizada de acordo com o momento histórico e problematizada na escola, visando à formação crítica e integral desses alunos.

Todavia, Darido (2003) assume que, historicamente, as aulas de Educação Física se restringiam (e até certo ponto se mantém assim) em oferecer conhecimentos advindos da repetição e da prática dos movimentos. Ou seja, esta forte presença da dimensão procedimental, pode se traduzir em dificuldades para os professores refletirem a disciplina dentro de outras dimensões, bem como, considerar as tecnologias no contexto escolar.

Betti (2001, p. 125) afirma que "a cultura corporal de movimento, senão no plano da prática ativa, ao menos no plano do consumo de informações e imagens, tornou-se publicamente partilhada na sociedade contemporânea". Neste âmbito, é inevitável que se construam possibilidades para esta disciplina, uma vez que isto poderia significar maiores interações aluno/professor por meio da troca de informações, otimizando a aprendizagem e tornando-a mais significativa.

Para que ocorram propostas pedagógicas mais efetivas no trato das TIC na Educação Física, duas áreas principais necessitam de modificações imediatas: o currículo, que ainda se apresenta arcaico; e a formação de professores incluindo a área tecnológica. Estas duas manifestações já significariam avanços no sentido de despertar olhares renovadores sobre a aprendizagem na modernidade.

A formação de professores para a utilização das TIC está sendo investigada em diversas pesquisas (Vilarinho, Sande, 2003), (Bernardi, Behar, 2004) e (Simonian, Brito, 2009), são alguns exemplos, em que, um dos objetivos é possibilitar maiores interações entre o formador e o aluno. No entanto, especificamente na Educação Física este processo ainda está no início, e desta forma, existem limitações para refletir e estruturar propostas que implementem as TIC nas aulas desta disciplina. Bianchi e Pires (2010), Mendes (2007, 2008) e Betti (2006) são alguns estudos com este cunho. 
Nelas foram utilizadas diversas estratégias pedagógicas para aproximar os professores do mundo digital e virtual. Contudo, percebe-se que ainda existem dificuldades para diminuir o abismo entre os conhecimentos dos professores sobre as TIC e a sua importância na atualidade.

A dificuldade que a Educação Física apresenta em lidar com as novas tecnologias ainda é corrente. Bianchi, Pires e Vanzin (2008) desenvolveram um estudo em escolas da rede municipal de Florianópolis, em que, apesar de existir incentivo à inserção das tecnologias nas escolas, a Educação Física ainda se mostra distante da utilização destes recursos, frente a possibilidades educativas concretas. Os professores desta disciplina foram apontados como aqueles que mais apresentam resistência para lidar com as TIC, deixando inclusive de participar dos espaços de formação proporcionados pela escola.

Os principais motivos apresentados pelos professores para este distanciamento é a falta de percepção acerca das relações entre as TIC e a Educação Física, uma vez que o local da disciplina é quadra, ou o campo de futebol (Bianchi, Pires, Vanzin, 2008). Esta justificativa apenas ressalta o discurso sobre a importância da prática que ainda é explorado na Educação Física, deixando as dimensões conceitual e atitudinal em segundo plano, ou na forma de currículo oculto (Forquin, 1993).

No entanto, apesar das TIC se constituírem em uma possibilidade didática interessante para desenvolver os conteúdos, aproveitando o novo contexto social de amplo desenvolvimento tecnológico, os trabalhos na área que ilustram algumas estratégias de "como" colocar propostas com este cunho em prática ainda são reduzidas.

Desta forma, faz-se importante desenvolver estudos que efetivem propostas de implementação pedagógica com o uso das TIC, bem como, a reflexão e apropriação pedagógica dos recursos tecnológicos já na formação inicial dos professores de Educação Física, o que pode corroborar com avanços concretos na exploração didática destes recursos quando estes professores estiverem na escola.

\section{Dificuldades na apropriação das TIC no contexto escolar}

Quando se discute as limitações de inserção das TIC na escola, faz-se necessário refletir sobre qual o papel ocupado pelo professor em meio a estas novas demandas, visto que ele se apresenta como um ator social indispensável neste contexto. Para Bonini (2009) inovar por meio de tecnologias, representa um risco inevitável que diversos profissionais têm que enfrentar, uma vez que este avanço atinge e condiciona todo processo de atualização, e neste caso, seria necessário que o professor se sentisse seguro para desenvolver os conteúdos de sua disciplina considerando os recursos tecnológicos do ciberespaço.

A atual conjuntura da sociedade exige do professor outras formas de dedicação à aprendizagem, que precisam ser contínuas e de qualidade, visto que o mesmo possui um papel fundamental na mediação entre o conhecimento culturalmente produzido pela humanidade e os alunos. Entretanto, sabe-se que este formador encontra limitações para incluir as ferramentas tecnológicas no contexto de aprendizagem, que entre outras, incluem a falta de tratamento destas questões na formação inicial e continuada, projetos específicos, condições estruturais, o currículo, bem como a própria dificuldade em lidar com as tecnologias. 
No que tange à formação inicial, seria interessante utilizar de múltiplas possibilidades para manter os futuros professores em constante atualização, culminando em debates profícuos acerca deste assunto. Portanto, seria fundamental para este grupo a compreensão da linguagem audiovisual e da informática, para que seja possível "convertê-la em conhecimento pessoal, social e profissional", de modo a complementar sua formação (Bianchi, Pires, Vanzin, 2008, p. 57).

É necessário que haja ainda, espaço para se pensar no papel que a educação pode assumir diante das TIC, refletindo sobre as possibilidades de aprendizagem que estas ferramentas podem significar para os alunos, bem como em novas metodologias e estratégias didáticas que podem ser utilizadas. É importante promover debates sobre inserção das TIC na educação não como um meio para a solução de todos os problemas escolares, mas sim como mais uma possibilidade de aprendizagem que pode ser utilizada nas aulas.

Segundo Masetto (2006), para que as tecnologias possam se inserir no contexto educacional de modo expressivo alguns princípios norteadores devem ser bem esclarecidos, como a necessidade de articulação entre as tecnologias, as metodologias e as atividades, de maneira que as mídias e as tarefas propostas promovam uma aprendizagem significativa. Para tanto, é necessário desenvolver novos planejamentos, estratégias didáticas e processos avaliativos.

Sob a égide desta discussão, entende-se que são necessárias maiores reflexões acerca do real papel das TIC no contexto educacional, procurando mediar pedagogicamente suas qualidades e limitações. Para isso, seria importante que durante a formação inicial, já se começasse a explorar algumas estratégias com os usos das TIC facilitando a compreensão destas questões por parte dos professores.

\section{Métodos}

Esta pesquisa é do tipo qualitativa. Esta forma de investigação visa descrever e decodificar os diversos significados e componentes da realidade, bem como expressar os diferentes sentidos dos fenômenos sociais (Maanen, 1979). Além disso, por meio da pesquisa qualitativa o pesquisador faz um recorte espacial e temporal na realidade, possibilitando descrições mais completas do problema investigado.

Para Lüdke e André (1986) a pesquisa qualitativa possibilita o contato direto do pesquisador com a situação estudada, enfatizando o processo em detrimento do produto. As mesmas autoras complementam ao apontar algumas características básicas deste tipo de investigação: o ambiente natural se constitui como fonte direta de dados em que o pesquisador é o seu principal instrumento; os dados coletados são predominantemente descritivos; e a análise dos dados possui uma tendência indutiva.

O presente estudo foi desenvolvido com 35 alunos do último ano de graduação em Licenciatura em Educação Física, em uma instituição pública, de um município do interior do estado de São Paulo, durante a disciplina de Educação Física escolar III - o objetivo era proporcionar aos alunos algumas reflexões e experiências pedagógicas com a utilização das TIC no ensino dos conteúdos da cultura corporal, e neste caso, em específico das danças folclóricas.

Toledo (2011) assevera que as danças folclóricas são manifestações que expressam de forma estética, a cultura de um povo. Entende-se, portanto, que ensinar 
danças folclóricas trata-se de explorar a história do país, perpassando por elementos como a constituição cultural do povo brasileiro, seus costumes, tradições, transformações e suas vivências corporais, reforçando como é importante a presença desta temática na escola.

O xaxado foi a manifestação selecionada visto que se apresenta como uma das propostas de conteúdo do Currículo de Educação Física vigente no estado de São Paulo (São Paulo, 2010).

A experiência procurou explorar diversos meios tecnológicos, como vídeos, análise de imagens e produção de materiais digitais, visando que os alunos pudessem vivenciar possibilidades com o uso das TIC no ensino dos conteúdos, e desta forma, ressignificar estes conhecimentos durante sua futura prática pedagógica.

\section{Resultados e Discussões}

Para maior compreensão dos resultados, os mesmos foram divididos em dois momentos distintos: descrição das estratégias adotadas e possibilidades didáticas das TIC para o ensino do xaxado na formação docente em Educação Física.

\section{Descrição das estratégias adotadas}

A experiência desenvolvida com o xaxado foi tratada nas três dimensões dos conteúdos, que são: conceitual, procedimental e atitudinal (Coll, Pozo, Sarabia, Valls, 2000). Cada uma destas dimensões corresponde às seguintes questões respectivamente: "o que se deve saber?", "o que se deve saber fazer?" e "como se deve ser?".

Este tratamento buscou favorecer a contextualização do conteúdo para além do "fazer", visto que, considerando a prevalência desta dimensão na Educação Física, ainda é necessário galgar um maior equilíbrio entre as outras formas de conhecer a cultura corporal. Ademais, o objetivo foi vivenciar e debater com os alunos sobre algumas estratégias didáticas para ensinar o xaxado por meio da utilização das TIC.

Primeiro momento. A princípio os alunos não sabiam do que se trataria a aula, e, desta forma, o processo de descoberta também foi importante para a construção dos conhecimentos. A aula iniciou-se com um "quebra-cabeça digital", em que os alunos, devidamente dotados de computadores, receberam imagens por email que deveriam ser montadas. A figura reconstruída evidenciou a imagem de um cangaceiro, e por meio desta, deu-se a problematização da aula.

Os alunos foram questionados acerca das características que identificavam na imagem, como vestimentas, armas utilizadas, calçados, a presença/ausência feminina, entre outras. Assim, aos poucos o grupo foi descobrindo o conteúdo que seria tratado na aula, bem como sua história, valores, características, e elementos principais, por meio da figura montada com auxílio das TIC.

Segundo momento. Após a identificação do conteúdo pelos alunos, foram propostas vivências de alguns passos e movimentações do xaxado, para que ao final fosse construída uma pequena coreografia. A composição foi filmada, e logo depois exibida ao grupo. Este espaço serviu para intensificar a dimensão procedimental, garantindo a especificidade da área. 
Terceiro momento. A terceira etapa baseou-se em uma proposta de avaliação dos conhecimentos que foram explorados durante a aula. Para tanto, foi apresentado um vídeo-resumo sobre o xaxado utilizando imagens e músicas diversas. Entretanto, as figuras empregadas estavam embaralhadas e algumas não se relacionavam com a manifestação. A tarefa do grupo era assistir o pequeno filme e selecionar apenas as imagens corretas, a partir dos conhecimentos construídos em aula.

Assim, os alunos receberam em seus computadores todas as imagens presentes no vídeo-resumo via email, e em grupo, selecionaram aquelas que consideraram corretas, produzindo uma apresentação no power point. Ao final, cada grupo teve que apresentar seus slides para o resto da turma explicando porque haviam escolhido ou não determinada figura.

Como forma de encerramento da proposta, realizou-se um debate com os alunos acerca das experiências pedagógicas vivenciadas por meio das TIC, levantado reflexões em torno dos pontos positivos e negativos no uso destas tecnologias durante a formação inicial, bem como no emprego das mesmas para o ensino dos conteúdos da cultura corporal no contexto escolar.

\section{Possibilidades didáticas das TIC na formação docente em Educação Física}

Os resultados apontaram que as TIC podem proporcionar diferentes possibilidades de ensinar e aprender durante a formação inicial. Os alunos em formação se mostraram bastante receptivos no que diz respeito ao emprego destas tecnologias no ensino dos conteúdos, levantando aspectos como o espaço que estas ferramentas já ocupam na sociedade atual, e na vida dos jovens, corroborando com dados apresentados pela literatura (Demo, 2008) e (Prenski, 2001).

Para o grupo participante, assim como apontado por (AMARAL et al., 2009) empregar as tecnologias na escola pode trazer diversos benefícios para aprendizagem, no entanto, capacitar os professores se constitui em uma etapa primordial deste processo, viabilizando que estes atores saibam explorar e adequar às ferramentas existentes aos objetivos das disciplinas e projetos.

Desta forma, o domínio básico das tecnologias faz-se extremamente importante para os professores, para que eles possam pensar em estratégias didáticas efetivas que usufruam da interatividade que as TIC podem proporcionar no meio escolar, transformando as maneiras de ensinar e aprender. Como aponta Borges (2008) além do domínio técnico, a existência de programas formadores para o uso das TIC envolve um aporte pedagógico e crítico sobre estas ferramentas proporcionando condições mais efetivas de atuação para os educadores.

Refletir sobre a formação inicial dos professores para a utilização e apropriação significativa das TIC, aponta a importância do papel de mediador ocupado pelo formador na construção do conhecimento, bem como, das possíveis relações com contexto tecnológico.

Os alunos relataram ainda que a oportunidade de refletir sobre estas questões na graduação foi algo interessante do ponto de vista pedagógico formador, uma vez que usar as tecnologias quando estiverem trabalhando na escola, significa um desafio ainda maior, considerando todas as limitações da realidade escolar, e em específico da relação entre as TIC e Educação Física. 
Estes obstáculos foram apontados principalmente no que tange a questão estrutural, afinal, são poucas as instituições que possuem computadores para todos, salas de vídeo, ou até mesmo internet pronta para ser utilizada. Todavia, cabe ressaltar que as dificuldades para a apropriação crítica e criativa das TIC na escola extrapolam os meios físicos, incluindo a falta de políticas educacionais, a rigidez dos currículos, o contexto escolar e sua equipe gestora, além da própria formação inicial e continuada dos professores voltada para estas questões (Sancho, 2006).

Neste escopo, entende-se que os professores, enquanto atores sociais relevantes nestas discussões precisam estar mais preparados para lidar com estes entraves que envolvem a inserção das TIC em âmbitos educacionais. Além disso, não podem compreender as tecnologias como solucionadoras de todos os problemas escolares para não se tornarem reféns destas ferramentas.

É necessário frisar que não adianta a aquisição de máquinas tecnológicas potentes, se a metodologia empregada continuar a mesma, ou seja, escrever um texto na lousa e pedir para os alunos copiarem não é diferente de apresentar o mesmo texto por meio de uma exibição no data show e solicitar a mesma tarefa. Este debate reforça a discussão de que não são apenas tecnologias, mas também as metodologias que precisam ser revistas e adequadas aos novos alunos que chegam à escola.

Desta forma, por meio da exploração de determinadas possibilidades didáticas, mediada pelas TIC na formação inicial de professores de Educação Física, foi possível pontuar algumas vantagens e desvantagens da inserção destas ferramentas no contexto educacional da área, bem como avaliar o que os futuros professores deste componente curricular projetam acerca desta discussão.

\section{Conclusões}

Com o objetivo de analisar algumas possibilidades didáticas com a utilização das TIC no ensino das danças folclóricas durante a formação inicial de professores de Educação Física, este estudo pôde ilustrar como seria um trabalho mediado com estas ferramentas na área, extrapolando discussões apenas em âmbitos teóricos. Em consonância com esta discussão, os alunos participantes puderam analisar e vivenciar algumas estratégias didáticas no ensino de um conteúdo da cultura corporal por meio de recursos tecnológicos, sem perder a especificidade.

A reflexão contemplou as impressões destes futuros professores acerca de situações concretas de ensino-aprendizagem, corroborando com a elaboração de um panorama mais contextualizado e significativo. Os alunos puderam debruçar seus anseios e dúvidas a partir desta problematização que lhes foi ofertada, ainda na graduação, ampliando a perspectiva acerca da inserção das TIC no contexto da Educação Física.

Esta pesquisa pode significar avanços importantes visto que a área ainda tem dificuldades para refletir seus conteúdos em vertentes tecnológicas, apesar dos progressos identificados em alguns estudos (Betti, 2001), (Bianchi, Hatje, 2007) e (Bianchi, 2001).

Sugere-se que mais experiências como estas possam ser desenvolvidas no Ensino Superior, pensando na formação inicial dos professores, bem como na escola, para que outras propostas de tratamento dos conteúdos da cultura corporal por meio das 
TIC possam ser documentadas e aprimoradas, ressignificando as maneiras de ensinar e aprender.

\section{Referências}

Abranches, S. P. (2003). Modernidade e formação de professores: a prática dos multiplicadores dos núcleos de tecnologias educacional do Nordeste e a informática na educação. (Doutorado em Educação) - Faculdade de Educação de São Paulo Universidade de São Paulo, São Paulo.

Amaral, M. A. et. al. (2009). Trabalho com Alunos Multiplicadores para Aplicação de Objetos de Aprendizagem no Ensino Curricular. In: Anais do XX Simpósio Brasileiro de Informática na Educação (SBIE), Belém-PA, Brasil.

Belloni, M. L. (2005). O que é mídia-educação. Campinas: Autores associados. $2^{\circ}$ edição.

Bernardi, M., Behar, P. A. (2004). A introdução das TIC na formação de professores: um estudo no curso de Pedagogia. In: Simpósio Brasileiro de Informática na Educação (SBIE) - UFAM, p. 525-583.

Betti, M. (2006). Imagens em ação: uma pesquisa-ação sobre o uso de matérias televisivas em programas de educação física do ensino fundamental e médio. Revista Movimento, Porto Alegre, p. 95-120.

Betti, M. (2001). Mídias: aliadas ou inimigas da educação física escolar. Motriz, Rio Claro, p.125-129.

Bianchi, P; Hatje, M. (2007). A formação profissional em Educação Física permeada pelas tecnologias de informação e comunicação no centro de Educação Física e desportos da Universidade Federal de Santa Maria. Pensar a Prática, p. 291-306.

Bianchi, P. (2009). Relato de experiência em mídia-educação (física) com professores da rede municipal de ensino de Florianópolis/SC. In Pires, G. e Dorenski, S. (Orgs). Pesquisa em educação física e mídia: contribuições do Labomídia/ UFSC. Florianópolis: Tribo da Ilha.

Bianchi, P e Pires, G. L. (2010). Possibilidades para o ensino-aprendizagem com Tics na Educação Física escolar: uma experiência com blogs. Cadernos de Formação RBCE, p. 45-55.

Bianchi, P, Pires, G. L. e Vanzin, T. (2008). As Tecnologias de Informação e Comunicação na rede municipal de ensino de Florianópolis: possibilidades para a educação (física). Revista Linhas, p. 56 - 75.

Bonini, A. M. (2009). Ensino de Geografia: Utilização de Recursos Computacionais (Google Earth) no Ensino Médio. Tese (Doutorado em Geografia) - Instituto de Geociências e Ciências Exatas, Universidade Estadual Paulista, Rio Claro.

Borges, M. F. V. (2008). Inserção da Informática no Ambiente Escolar: inclusão digital e laboratórios de informática numa rede municipal de ensino. In: XXVIII Congresso da Sociedade Brasileira de Computação (SBC), Workshop de Informática na Escola (WIE).

Brasil. (2000). Ministério da Educação e do Desporto. Parâmetros Curriculares Nacionais. Brasília: Secretaria de Educação Média e Tecnológica. 
Simonian, M., Brito, G. S. (2009). Formação continuada em ambiente virtual de aprendizagem: elementos reveladores da experiência de professores da educação básica. In: XX Simpósio Brasileiro de Informática na Educação (SBIE).

Coll, C., Pozo, J. I., Sarabia, B. e Valls, E. (2000). Os conteúdos na reforma. Porto Alegre: Artmed.

Darido, S. C. (2003). Educação Física na escola: questões e reflexões. Rio de Janeiro: Guanabara Koogan.

Darido, S. C. e Souza Júnior, O. M. (2007). Para ensinar Educação Física: possibilidades de intervenção na escola. Campinas: Papirus.

Darido, S. C. e Rangel, I. C. A. (2005). Educação Física na escola: implicações para a prática pedagógica. Rio de Janeiro: Guanabara Koogan.

Demo, P. (2008). TICs e Educação. Disponível em: <http://pedrodemo.sites.uol.com.br/textos/tics.html>. Acesso em: 25 set. 2011.

Forquin, J. C. (1993). Currículo e cultura. Porto Alegre: Artes Médicas.

Lüdke, M. e André, M. (1986). Pesquisa em educação: abordagens qualitativas. São Paulo: EPU.

Maanen, V. J. (1979). Reclaiming qualitative methods for organizational research: a preface. In: Administrative Quaterly Science, p. 520-526.

Masetto, M. T. (2006). Mediação pedagógica e o uso da tecnologia. In: Moran, J. M., Masetto, M. T. e Behrens, M. A. Novas Tecnologias e Mediação Pedagógica. $12^{\circ}$ edição, Campinas: Papirus, p. 133-173.

Mendes, D. S. (2008). Articulações Entre Lazer e Mídia na Educação Física Escolar. Motrivivência, p. 241-250.

Mendes, D. S. (2007). Formação continuada de professores de educação física, pesquisa-ação e mídia-educação: relato de uma experiência em andamento. In: XV Congresso Brasileiro de Ciências do Esporte, Recife, PE.

Prenski, M. (2001). Digital Game-Based Learning. New York: McGraw-Hill.

Sancho, J. M. (2006). De tecnologias da Informação e Comunicação a Recursos Educativos. In: Sancho, J. M. e Hernadéz, F. Tecnologias para transformar a educação. Tradução V. Campos. Porto Alegre: Artmed, p. 15-41.

São Paulo. (2010). Secretaria de Estado da Educação de São Paulo (SEE/SP). Currículo do Estado de São Paulo. Revista do Professor. São Paulo: IMESP.

Toledo, E. (2011). O folclore na escola: um esquecido, porém precioso, conteúdo da Educação Física. In: Moreira, E. C.; Pereira, R. S. Educação Física escolar: desafios e propostas 2. $2^{\circ}$ edição. São Paulo: Fontoura, p. 65-92.

Vilarinho, L. R. G e Sande I. C. (2003). Formação continuada de professores em cursos on-line: novas perspectivas no processo ensino-aprendizagem? In: XIV Simpósio Brasileiro de Informática na Educação (SBIE) - NCE - IM/UFRJ. 